\title{
EDITORIAL
}

\section{Do Authors Know and Follow the ICMJE Recommendations?}

\author{
Abraham Haileamlak, MD, Professor of Pediatrics and Child Health
}

\section{DOI: http://dx.doi.org/10.4314/ejhs.v26i1.1}

The International Committee of Medical Journal Editors (ICMJE) is a group of general medical journal editors meeting regularly and works on Recommendations for the Conduct, Reporting, Editing and Publication of Scholarly Work in Medical Journals (www.ICMJE.org). In doing so it receives comments and suggestions from editors, researchers, associations and funding companies. The committee members are journal editors from all parts of the world and representatives of the World Association of Medical Editors (WAME), National Library of Medicine (NLM) and Council of Science Editors (CSE).

Other journals opt to follow the ICMJE's Uniform Requirements for Manuscripts Submitted to Biomedical Journals can apply to include their journal on the list of journals that follow ICMJE policy on www.ICMJE.org. Until now over two thousand five hundred journals are in the list.

However, many authors submitting manuscripts to publish on those journals claiming to follow the ICMJE uniform requirements appear un-aware of the Recommendations. As a result, they submit manuscripts which are prepared in the contrary.

Likewise, despite their cognizance, many of these journals claiming following the ICMJE Uniform Requirements do not enforce utilization of the requirements. This could lead to unnecessary origin of conflict by some authors and funding organizations requesting ICMJE to take measures on such journals. However, researchers, editors and funders should know that ICMJE is not a mandated organization to take such measures; rather as a volunteer group recommends what best research and publication practice should be.
Unless it is unfamiliarity, following the ICMJE requirements do not create inconvenience or incur cost. Therefore, researchers who intend to publish on journals that follow the ICMJE Uniform Requirements are advised to read the ICMJE Recommendations and other documents on www.ICMJE.org so that they can prepare their manuscript accordingly.

Journals which follow the ICMJE requirements better set means of checking submitted manuscripts for compliance to the ICMJE requirements before they accept and publish them.

The current issue (Vol. 26, No 1), the first issue of the year contains two editorials focusing on the ICMJE recommendations, ten original articles on varied subjects and three case reports focusing on different areas. The first editorial is a sort of awareness creation and briefing about the already available ICMJE recommendations while the second one is on Clinical Trial Data sharing which is developed newly and posted for comment. Two of the original researches published in this issue are on newborn care, two on HIV/AIDS, one each on maternal health, headache, burn injury, kidney injury, traditional medicine and tuberculosis from geographically varied low and middle income countries. The three case reports are on various diagnostic and therapeutic challenging conditions.

I invite readers to read through these articles and appreciate or utilize the contents. I also encourage readers to forward comments and suggestions. 